\section{Comparison of selection of preoperative laboratory tests: the computer vs the anaesthetist}

HealthQuiz II (HQII) is a computerized history-taking device which can be used by patients before anaesthesia and surgery. HealthQuiz II provides a summary of symptoms, a modified ASA Classification, and a list of suggested laboratory tests. Developed at the University of Chicago, the device has not been evaluated in Canada. The purpose of this study was to compare preoperative evaluation and selection of laboratory tests by $a$ group of Canadian anaesthetists using traditional methods versus using HealthQuiz II. Twenty-seven anaesthetists from three (Western) Canadian University teaching hospitals participated in the study. The subjects were male, aged between 30-50 yr, trained in Canada and practicing in Calgary, Edmonton and Vancouver. They were asked to self-evaluate and select laboratory tests and then to complete the HQII protocol, the day before a proposed mock operation. Results of this comparison showed that the ASA scores assigned by HQII were higher for 11 subjects and lower for two. Eight anaesthetists thought $H Q I I$ asked questions which they omitted while five thought $H Q I I$ overlooked items. Thirteen anaesthetists believed HQII would be a useful adjunct to their practice. Only ten anaesthetists requested any tests while HealthQuiz II suggested tests for 23 subjects, with an average of 1.9 tests/subject (anaesthetists) vs 5.4 tests/subject (HQII). The total cost of tests selected by anaesthetists was $\$ 272.15$ in contrast with $\$ 1,513.20$ for those suggested by $H Q I I$. We conclude that rationale for test selection

\section{Key words}

PREOPERATIVE ASSESSMENT; ANAESTHESIA: costs.

From the *Department of Anaesthesia, Foothills Hospital, Calgary, AB, †Department of Laboratory Medicine, Foothills Hospital, Calgary, AB, $\ddagger$ Department of Anaesthesia, Vancouver Hospital \& Health Sciences Centre, Vancouver, BC, $\S$ Department of Anaesthesia, University of Alberta Hospitals, Edmonton, AB.

Address correspondence to: Dr. J.M. Davies, Department of Anaesthesia, Foothills Hospital, 1403-29 Street NW, Calgary, AB, T2N 2 T9.

Accepted for publication 11th August, 1994. may have contributed to the difference in number and costs of tests.

Le HealthQuiz II constitue un dispositif de recueil des données anamneutiques utilisable avant l'anesthésie et la chirurgie. Le HealthQuiz II fournit un résumé des symptômes, une classification ASA modifiée et propose des épreuves de laboratoire. L'objectif de celte étude était de comparer l'évaluation préopératoire et la sélection des épreuves de laboratoires chez un groupe d'anesthésistes qui utilisait soit les méthodes traditionnelles, soit le HealthQuiz II. Vingt-sept anesthésistes de trois hopitaux universitaires de louest du Canada participaient à l'étude. Ils étaient des hommes âgés de 30 à 50 ans, formés au Canada et exerçant à Calgary, Edmonton et Vancouver. On leur demandait de sévaluer, de choisir les épreuves de laboratoires et de compléter par la suite le protocole HealthQuiz II, le jour qui précédait une intervention fictive. Les résultats de cette comparaison ont montré que les cotes $A S A$ assignées par HealthQuiz II étaient plus élevées pour onze sujets et plus basses pour deux. Huit anesthésistes ont cru que HealthQuiz II posait des questions qu'ils avaient négligées alors que cinq étaient d'avis que HealthQuiz II négligeait certains questions. Treize anesthésistes ont émis l'opinion que le HealthQuiz II pourrait être utile à leur pratique. Seulement deux anesthésistes ont demandé des épreuves de laboratoire alors que HealthQuiz II suggérait des épreuves pour 23 sujets, avec une moyenne de 1,9 épreuves/sujets (anesthésiste) vs 5,4 épreuves/sujet (HealthQuiz II). Le coût total des épreuves choisies par les anesthésistes était de 272,15\$ comparativement à 1513,20\$ pour ceux que suggérait le HealthQuiz II. Nous croyons que la raison de la sélection des épreuves peut avoir contribué à la différence entre le nombre et le coût des épreuves.

The introduction of a new device into clinical anaesthetic practice in any country should be considered only after a thorough evaluation. This should include critical appraisal in the area of intended use to ensure that the device is not only accurate and reliable, but also applicable to anaesthetic practice in that country. Health- 
Quiz II is a computer programme developed at the University of Chicago as a patient-driven medical history system which suggests patient specific laboratory tests ${ }^{1}$ based upon criteria established by an "expert panel." HealthQuiz II generates a print-out of a patient's answers to a series of pre-programmed questions, a symptom summary, and list of factors important to anaesthetic care, such as allergies or abnormal dentition. ${ }^{1}$ A Physical Status classification (referred to as HQASA) is also assigned to each patient.

While the device has had evaluation in the United States, ${ }^{1-4}$ no similar trials of HQII have been carried out solely in Canada. This study was undertaken to enable anaesthetists from three Canadian university medical centres to evaluate the suitability of HQII in the screening of individuals presenting for elective surgery.

\section{Methods}

Male specialist anaesthetists, between the ages $30-50 \mathrm{yr}$, who were trained in Canada and were practicing in Calgary, Edmonton, or Vancouver, at the time of the study, were asked to participate. The subject was then given the following case scenario:

"You were skiing this season and had a serious fall on the beginner hill, twisting your knee. The knee injury resulted in your being removed from the hill by the ski patrol and a week's 'holiday' before you could walk. You are now scheduled to undergo arthroscopy by the finest orthopaedic surgeon in the country. The case will take place tomorrow and the type of anaesthetic is not yet determined."

Each subject recorded his age, number of years since specialist certification, and performed mentally a preoperative assessment, as though he was to be his own anaesthetist. The subject assigned himself an ASA Physical Status Classification and chose appropriate preoperative laboratory tests based on his personal history. A mock laboratory requisition was provided. (The actual tests were not carried out.) After performing the selfevaluation, the anaesthetist completed the HQII computerized assessment. A summary, including tests suggested by HQII, was printed. A short questionnaire was given to determine the extent to which the anaesthetist agreed with the ASA Classification chosen by HQII, whether HQII asked questions he overlooked, whether HQII overlooked questions which he had asked, if HQII chose tests which the anaesthetist should have chosen and if HQII omitted tests which the anaesthetist chose. Specifically, subjects were asked to consider omission of "significant pre-existing condition," "significant personal history," or "significant family history." Finally, the subject was asked to consider whether or not he saw HQII as a useful adjunct in his preoperative assessment of patients.
TABLE I Demographics of subjects

\begin{tabular}{lll}
\hline Cenire & Age $y r$ & Years since FRCPC \\
\hline Calgary & $39(\mathrm{r}=33-47)$ & $6.6(\mathrm{r}=2-15)$ \\
Edmonton & $39(\mathrm{r}=34-46)$ & $7.3(\mathrm{r}=1-16)$ \\
Vancouver & $41(\mathrm{r}=36-48)$ & $9.1(\mathrm{r}=1-16)$ \\
\hline
\end{tabular}

Subjects' confidentiality was preserved through the use of a random four-digit identification number. Since the study was conducted using questionnaires, subjects were always aware of the full extent of information obtained for analysis. Subjects were able to withdraw from the study at any time if information solicited violated their sense of privacy, or for any other reason. (None did.) Also, while subjects were made familiar with the protocol, they were not made aware of the hypothesis (to avoid bias).

Simple analysis of age and years since specialist certification was done. The ASA Physical Status Classification assigned by the anaesthetist and those generated by the HQII were compared on the basis of whether or not the Classifications matched; if not, then the direction of deviation was recorded. The degree of agreement and extent of difference for each of the questions was tabulated.

Costs of laboratory tests were calculated from figures obtained from the Alberta Health Care Insurance Plan Fee Schedule (1993). The number and estimated costs of laboratory tests were calculated for both order sets (i.e., the set chosen by the anaesthetist vs that suggested by HQII). Statistical significance of costs of laboratory tests was determined using a paired $\mathrm{t}$ test, with the level of significance set at $P<0.05$.

\section{Results}

Twenty-seven anaesthetists entered and completed the study (nine in each centre). Their demographics are shown in Table I. There was no difference in the age of participants in the three centres. The number of years since specialization showed a similar distribution.

The ASA Physical Status Classification as selected by the anaesthetists versus those selected by HQII are shown in Table II. The scores were the same for 14 subjects. The HQII selected scores that were higher for 11 subjects and lower for two subjects in comparison with anaesthetist selected scores.

Eight anaesthetists thought that HQII asked questions which they did not. These questions represented "significant pre-existing condition" in three of these eight subjects and "significant personal history" in four of these eight subjects. (One subject selected "both pre-existing condition" and "significant personal history." Two sub- 
TABLE II Physical status scores as assigned by anaesthetists (ASA) and by HQII (HQASA)

\begin{tabular}{llll}
\hline ASA & Anaesthetists & HQASA & HQII \\
\hline 1 & 25 & 1 & 14 \\
- & - & 1.25 & 2 \\
- & - & 1.5 & 11 \\
2 & 2 & 2 & 0 \\
3 & 0 & 3 & 0 \\
4 & 0 & 4 & 0 \\
\hline
\end{tabular}

jects gave no answer.) According to five subjects, HQII was judged to have overlooked items. These items represented "significant pre-existing condition" for three subjects. (Two subjects gave no answer.) There was divided opinion about the usefulness of HQII for preoperative evaluation, with thirteen subjects answering that HQII would be a "useful adjunct in their preoperative evaluation of patients."

The number and cost of laboratory tests are shown in Table III. Fewer individuals had tests suggested for them on the basis of personal selection than by HQII. In addition, fewer tests per individual were selected by the anaesthetists than suggested by HQII. Although the cost per unit test was approximately the same, the cost per individual was about 2.5 times greater for HQIIsuggested tests and the total cost was about 5.5 times greater than for anaesthetist-selected tests. One-third of anaesthetists stated that the computer suggested tests which they should have chosen. In no case did HQII omit tests the subjects chose (i.e., it did not under-order tests relative to anaesthetists). However, 17 anaesthetists ordered no tests and for only three of these subjects did HQII also suggest no testing (i.e., over-testing relative to anaesthetists). Table IV shows the tests selected.

\section{Discussion}

This study provided anaesthetists from three Western $\mathrm{Ca}$ nadian teaching hospitals with an opportunity to evaluate HQII. Only male anaesthetists were chosen to reduce sex related health variables and to provide the largest number of possible subjects. More than one hospital was surveyed in an attempt to reduce bias on the basis of local practice. As expected, the age and practice experience of these subjects showed similar distribution.

More than a decade ago, Tompkins et al. ${ }^{5}$ showed that a "computer-assisted pre-anesthesia interview (was) more accurate and less variable than the anesthesiologists' preanesthesia interview in gathering preoperative historical information." Since then, Roizen demonstrated that the HealthQuiz was as effective in obtaining information about patients as was an oral interview. ${ }^{3,4}$ Eight of our subjects were in agreement with these findings but five
TABLE III Laboratory tests selected by the anaesthetists vs those suggested by HQII

\begin{tabular}{llc}
\hline & Anaesthetists & HQII \\
\hline \# Individuals tested & 27 & 27 \\
\# Individuals requiring tests & 10 & 23 \\
\# Tests & 19 & 124 \\
\# Tests / tested individual & 1.9 & 5.4 \\
& & \\
Total cost* & $\$ 272.15$ & $\$ 1,513.20$ \\
Cost / tested individual* & 27.22 & 65.79 \\
Cost / test & 14.32 & 12.20 \\
\hline
\end{tabular}

$* P<0.05$

TABLE IV Actual laboratory tests selected by anaesthetists and suggested by HQII

\begin{tabular}{llc}
\hline Name of Test & $\begin{array}{c}\text { Anaesthetist } \\
\text { selected }\end{array}$ & $\begin{array}{c}\text { HQII } \\
\text { suggested }\end{array}$ \\
\hline None & 17 & 4 \\
CBC & 6 & 1 \\
CBC with differential & 2 & 13 \\
Urine & 2 & \\
Electrolytes & 1 & 2 \\
Glucose-random & & 3 \\
Creatinine & & 3 \\
Blood urea nitrogen & & 3 \\
Protein & & 11 \\
Albumin & & 3 \\
Calcium & & 1 \\
Inorganic phosphate & & 5 \\
Magnesium & & 1 \\
Lactate dehydrogenase & & 1 \\
SGOT (AST) & & 17 \\
SGPT (ALT) & & 1 \\
Partial thromboplastin time & & 9 \\
HIV & & \\
12 Lead ECG & 4 & 19 \\
Spirometry & 1 & \\
Chest $x$-ray & 2 & \\
Arterial blood gas & 1 & \\
\hline
\end{tabular}

were not, with three of the latter believing that HQII missed a "significant pre-existing condition" (unspecified by the anaesthetists).

While there was little major difference in ASA classifications assigned by the anaesthetists and by HQII, some differences were noted because of the "intermediate" ASA Classifications, i.e., HQASA 1.25 and 1.5 , assigned by HQII. Since the ASA Classification system does not have a provision for half scores, these values could not be compared. Nor can examples of these latter scores be given. The HQASA was modified from the "Objective ASA" (Ob-ASA), which was in turn derived from the ASA Physical Status Score. The Ob-ASA was developed 
to provide a "more objective scale for determining a patient's physical status" and was "based on measures of coronary artery disease, hypertension, pulmonary disease, renal and electrolyte disorders, hepatic disease, and diabetes." The HQASA was modified to include "medically important symptoms related to several diseases." Using an algorithm, the Health Quiz calculates "risk indexes based on patients' responses to questions about symptoms or treatment of hypertension, congestive failure, ischemic cardiac disease ... Progressive letters after an index (e.g., B,C,D) indicate that additional disease processes and more questions about functional status are used to define the risk index." ${ }^{2}$ The Preoperative Test Selection Version 2.0 Software Manual states that the "HQASA index correlates with the ASA physical status score and the Objective ASA score," citing Reference \#2. The correlation coefficients given in this reference "between the Ob-ASA and the ASA physical status and between the HQ ASA-A and the ASA physical status were 0.53 and 0.40 , respectively."

The anaesthetists ordered between one and five tests per individual in contrast to the HQII which suggested between two and ten tests per individual. The fact that 17 anaesthetists did not order any tests while HQII suggested laboratory tests for 23 individuals represents overtesting when compared to practice in the three centres. The HQII also ordered an increased amount of testing per individual, with an average of 1.9 tests each (ordered by the anaesthetists) and an average of 5.4 tests each (ordered by HQII). If the HQII test selection was projected over 10,000 ASA 1 or 2 males, then the cost of this increased testing would represent $\$ 385,700$. However, in five instances where an anaesthetist ordered no tests for himself, each subject reported agreement with HQII which had suggested some tests. One weakness of our study is that we did not ask specifically with which test the anaesthetist agreed.

While the concept of the HQII seems intrinsically useful (as noted by anaesthetists participating in the evaluation) it is reasonable that it be validated using external criteria. One of the triggers for this study was receipt by one of the authors (JMD) of the HQII with its Preoperative Test Selection Version 2.0 Software Manual, in which "Clinical Guideline Rationale by Disease" are given. Some of these guidelines appeared incongruent with Canadian anaesthetic practice. One example is that of "eating habits." The Manual states "If $Q 551$ "Have your appetite or eating habits changed in the last year?' is answered YES or NOT SURE, a BUN/CREATININE is suggested." The rationale given is that "changes in eating habits are an early subtle sign of azotemia." While this is a medically correct statement, ${ }^{6}$ azotaemia is probably not a common cause of changes in eating habits in a population of adults who are continuously encouraged to alter their eating habits.

Another problem appeared to be that of the references given with test rationale. For example, in the Manual section entitled "Rationale by Disease," under "PREGNANT," the manual states "If Q 501 'Do you have any reason to believe that you are pregnant or might possibly be pregnant?' is answered YES or NOT SURE, an SGOT or SGPT test is suggested." The rationale given is "Positive answers to this question in the HealthQuiz Outcome Studies correlated with abnormalities in SGOT/SGPT." The reference cited an abstract by Apfelbaum, Roizen, Murray et al. ${ }^{3}$ of a study "to determine how often asymptomatic patients benefit from preoperative laboratory screening." Tests results were compared for both asymptomatic and symptomatic patients. Of the 10,899 tests ordered for "asymptomatic patients," $8.4 \%$ were "abnormal," $1.1 \%$ were "significantly abnormal," and $0.1 \%$ "affected outcome." Of 10,419 tests ordered for "symptomatic patients," $17.3 \%$ were "abnormal," $5.8 \%$ were "significantly abnormal" and $1.2 \%$ "affected patient care." No details as to specific symptoms or laboratory results were given in the abstract.

One possible reason for the difference in extent of testing between that suggested by HQII and that suggested by the anaesthetists might lie in differences between patients in the United States and Canada. Because of the absence of universal health care in the USA, patients who present for anaesthesia and surgery may be less well than those in Canada where universal health care exists. Thus, increased numbers of abnormal test results from American patients would reflect this lower health status. In support of this thesis is the fact that our subjects were all relatively healthy, but still had large numbers of tests suggested by HQII. In addition, the fact that our subjects were to undergo a relatively minor operation (arthroscopy of the knee) is not pertinent. None of the questions asked by HQII makes any reference to the proposed type of operation.

Half the subjects in our study thought that the HQII might prove a useful adjunct to their practice particularly as a way of coping with the ever-increasing numbers of patients undergoing operation on the day of admission to hospital (which has changed traditional methods of preoperative assessment). A device such as HQII, which provided an objective method for determining preoperative laboratory tests, would be potentially very useful. However, the favourable evaluation by 13 of our 27 study subjects was made without knowledge of the degree and costs of overtesting from application of HQII. The lack of specificity in such a test-ordering rationale seems more to describe screening, rather than to describe patientspecific test selection. Also, many of the recommenda- 
tions for laboratory tests appear to be somewhat removed from current Canadian practice. These facts, coupled with a lack of opportunity to examine the test rationale for HQII closely before purchase, make it difficult to determine the device's applicability. At a 1993 cost of $\$ 5,000.00 \mathrm{CDN}$, purchase of HQII might strain further the resources of Canadian health-care institutions. Professional consensus guidelines would offer the same potential to reduce unnecessary laboratory testing at a significantly lower cost, ${ }^{7,8}$ and at the same time ensure that necessary tests are not also reduced. ${ }^{9}$

Finally, since this study was completed, Nellcor Incorporated has acquired the rights to the HealthQuiz. Both the hardware and the software have been modified. The new device, Nellcor HealthQuiz PreScreen, is now available, but, like HealthQuiz II, should also undergo thorough evaluation.

\section{References}

1 Roizen M. Preoperative patient evaluation. Can J Anaesth 1989; 36: S13-9.

2 Roizen MF, Coalson D, Hayward RSA, et al. Can patients use an automated questionnaire to define their current health status? Med Care 1992; 30 (Supplement): MS74-84.

3 Apfelbaum JL, Roizen MF, Murray WJ, et al. Do asymptomatic individuals benefit from preoperative laboratory screening? Anesthesiology 1991; 75: Al054.

4 Lutner RE, Roizen MF, Stocking CB, et al. The automated interview versus the personal interview. Do patient responses to preoperative health questions differ? Anesthesiology 1991; 75: 394-400.

5 Tompkins BM, Tompkins WJ, Loder E, Noonan AF. A computer-assisted preanesthesia interview: value of a computer-generated summary of patient's historical information in the preanesthesia visit. Anesth Analg 1980; 59: 3-10.

6 Brenner BM, Lazarus $J M$. Chronic renal failure. In: Wilson JD, Braunwald E, Isselbacher $\mathrm{KJ}$, et al. (Eds.). Harrison's Principles of Internal Medicine. 12th ed. Toronto: McGraw-Hill, Inc., 1991: 1150-7.

7 Battista RN, Hodge MJ. Clinical practice guidelines: between science and art. Can Med Assoc J 1993; 148: 385-9.

8 Hayward RSA, Laupacis $A$. Initiating, conducting and maintaining guidelines development programs. Can Med Assoc J 1993; 148: 507-12.

9 Macario A, Roizen MF, Thisted RA, Kim S, Orkin KF, Phelps $C$. Reassessment of preoperative laboratory testing has changed the test-ordering patterns of physicians. Surg Gynecol Obstet 1992; 175: 539-47. 